\title{
Hair Growth Promoting Activity of Green Tea Leaves (Camellia sinensis l.) Ethanolic Extract
}

\author{
Vini Noviani ${ }^{1}$, Shelly Thauresia ${ }^{1}$, Elsa Fitria Apriani ${ }^{2}$, Partomuan Simanjuntak ${ }^{1}{ }^{*}$ \\ ${ }^{1}$ Magister of Pharmaceutical Sciences, Faculty of Pharmacy, Pancasila University, Jakarta, Indonesia \\ ${ }^{2}$ Department of Pharmacy, Faculty of Mathematics and Natural Sciences, Sriwijaya University, South Sumatra, \\ Indonesia
}

\begin{abstract}
Hair loss and baldness are one of the abnormalities in the hair that often occurs in both men and women. Many cosmetic products from natural to synthetic materials have been developed to overcome these problems, yet, synthetics product is potential to give side effects, such as local irritation. In this study, green tea (Camellia sinensis L.) leaves were used as active substances. The aim of this study was to attest the hair growth-promoting activity of n-hexane, water, and ethyl acetate fractions from ethanolic extract of green tea leaves. Green tea leaves contain flavonoids which can help to promote hair growth. To obtain the compound, green tea leaves were made into ethanolic extract. The extract was obtained by maceration using $70 \%$ ethanol then partitioned using n-hexane, ethyl acetate, and water, to obtain the n-hexane, ethyl acetate, and water fractions. Ethyl acetate and water fractions have been shown to contain flavonoids, so it could continue the hair growth-promoting activities with concentrations of $1 \%$ and $4 \%$. Hair growth-promoting activity was performed on rabbits. The results showed that $4 \%$ of water fraction containing flavonoids had the best hair growth-promoting activity.
\end{abstract}

Keywords: Green tea leaves, hair growth-promoting activity, water fraction, flavonoids.

\section{INTRODUCTION}

Hair loss and baldness are abnormalities in the hair that occurs mostly in men and women. This is generally caused by physiological conditions, emotional and physical stress, lack of nutrition, hormonal disorders and drugs (Harrison and Bergfeld, 2009).

Hair tonic from both herbal and synthetic cosmetic products have been developed to overcome hair loss and baldness. Along with the development of technology, many Indonesian people prefer to use herbal products because they only cause a few side effects (Thorat, 2010), unlike synthetic products like Minoxidil which can cause side effects such as sensitivity to the scalp (Adhirajan et al., 2008).

Indonesia is a country that has many herbal plants that can be used as ingredients for making hair tonic. Green tea leaves (Camellia sinensis L) are one of the Indonesian plants, which contain flavonoids. Flavonoids are proven to increase the rate of hair growth. Flavonoids are known to be the biggest phenol compounds contained in plants in all parts of plants such as leaves, bark, flowers, fruit, seeds, roots, pollen and sap (Markham, 1988). Based on research conducted by Lamria, $2.5 \%$ of green tea extract in hair tonic preparations was able to increase significantly hair growth rates compared to $2.5 \%$ of Minoxidil (Lamria, 2013).

*Corresponding author : Partomuan Simanjuntak Email : partomuansimanjtk@yahoo.com
Another study, green tea (Camellia sinessis L) has a pharmacological effect of hair growth-promoting on $50 \%$ fraction of green tea polyphenol extract (Camellia sinesis L) given to bald rats compared to other groups of rats which were given only water orally. The results showed $33 \%$ of mice given polyphenol extract showed increase hair growth significantly for 6 months and the group of rat that given water did not show any hair growth (Esfandiari and Kelly, 2005).

Based on the data above, in this study, flavonoids were separated from other compounds found in green tea leaves. To obtain flavonoids from green tea leaves, partition extraction was carried out with n-hexane, ethyl acetate, and water. The purpose of partition extraction is to separate flavonoid compounds with other compounds based on their level of polarity.

\section{METHODOLOGY Materials}

Green tea leaves (Gunung Mas, Bogor, Indonesia), 70\% ethanol, $96 \%$ ethanol, ethyl acetate and aquadest (obtained from PT Brataco Chemical, Indonesia).

\section{Methods}

Plant Determination

Plant determination was undertaken to ascertain the type of plant used for the study. 


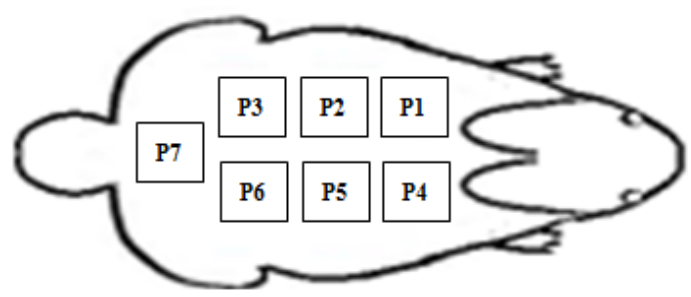

Figure 1. The dorsal aspect of rabbits where the position of treatment area

Green tea leaves are determined in Bogoriense herbarium, Biology Research Center LIPI, Cibinong, Bogor.

\section{Preparation of Simplisia}

Green tea leaves are collected and sorted. Then washed with running water until clean and drained it. Green tea leaves are dried by oven at temperature $40^{\circ} \mathrm{C}-50^{\circ} \mathrm{C}$ for seven days. After drying, the green tea leaves are smoothed with a grinder tool to obtain a powder of simplicia. The simplicia powder is kept in a brown bottle tightly closed, protected from sunlight and humid air.

\section{Preparation of Ethanolic Extract and Their Fractions.}

The simplicia powder from green tea leaves used is 2000 grams. One part of dry powder is added with 5 parts of $70 \%$ ethanol. The powder is soaked in $70 \%$ ethanol for one day and stirred every 6 hours. The obtained macerate is separated by filtration using flannel cloth. This process is repeated for five days using the residue of simplisia powder. All the macerates are collected. The macerate was concentrated with a vacuum evaporator at temperature of $50^{\circ} \mathrm{C}$ and heating it over a water bath until the solvent evaporated perfectly or viscous extract is obtained.

The viscous extract was partitioned using nhexane, ethyl acetate, and water. The n-hexane and ethyl acetate fraction was concentrated using a rotary evaporator. The water fraction is dried using the freeze-drying method.

\section{Raw Material Quality Test}

The quality test of the raw material consists of specific parameters test (organoleptic examination, soluble compounds in certain solvents), non specific parameters (loss on drying, determination of moisture content, determination of ash content, determination of acid-insoluble ash content), phytochemical test and total flavonoids in extract (Depkes RI, 1995; Depkes RI, 2000).

\section{Flavonoid Screening}

The flavonoid screening was conducted according to Indonesia Materia Medica (Depkes RI, $1995^{\mathrm{b}}$ ) and Harborne (Harborne, 1998). This test includes the test of color reaction (Shinoda test and pew test) on n-hexane, ethyl acetate, and water fractions. Also, thin layer chromatography of ethyl acetate and water fractions. The TLC plate is sprayed using sitroborate to detect flavonoids. Fractions contain flavonoid were selected to hair growth-promoting activity test.

\section{Hair Growth Promoting Activity of The Selected Fraction}

This study is referring to method from Tanaka et al., 1980. The dorsal of rabbits were divided into seven areas, with a size of $2 \mathrm{~cm} \times 2 \mathrm{~cm}$ each, on where the test solution was applied. The hairs on each area were shaved using a razor. After shaving and before applying basting, rabbit's back for treatment area was smeared with $70 \%$ ethanol as an antiseptic. These areas are then marked as depicted in Figure 1 as follows: P1: 2.5\% ethanolic extract; P2: $1 \%$ water fraction; P3: $4 \%$ water fraction; P4: $1 \%$ ethyl acetate fraction; P5: 4\% ethyl acetate fraction; P6: Negative control (aquadest); P7: Normal control (not smeared).

The test solution for ethanolic extract was made by dissolving the ethanolic extract in $96 \%$ ethanol. The test solution for water fraction was made by dissolving the water fraction in aquadest to get a concentration of $1 \%$ and $4 \%$, and the test solution for ethyl acetate fraction was made by dissolving the ethyl acetate fraction in ethyl acetate to get a concentration of $1 \%$ and $4 \%$,

The test solution was administered topically on the rabbit shaved skin, twice a day (morning and evening) with a volume of $1 \mathrm{~mL}$, for 28 days. On day 7, 14, and 21 and 28 from each treated area was taken randomly 6 hairs and the length of each hair was measured. Besides the length of each hair, hair growth rate and hair weight also were measured. The hair growth rate is obtained from the length of the hair.

\section{Statistical Analysis}

Kruskal-Wallis and Mann-Whitney (ANOVA) were used to determine the statistical significance $(p<0.05)$ of the differences between the values of various group.

\section{RESULT AND DISCUSSION Raw Material Quality Test}

The color of green tea leaves powder obtained is green. The ethanolic extract produced was thick and brown. The ethanolic extract obtained was $272.49 \mathrm{~g}$ (yield of $13.62 \%$ ). 
Table I. Several characteristic of green tea ethanolic extract

\begin{tabular}{lc}
\hline Characteristics & Results \\
\hline Total ash content & $4.42 \%$ \\
Acid insoluble ash content & Not detected \\
Water soluble & 29.02 \\
Alcohol soluble & 21.40 \\
\hline
\end{tabular}

Table II. The result of color reaction

\begin{tabular}{cccc}
\hline \multirow{2}{*}{ Compound } & \multicolumn{3}{c}{ Fraction } \\
\cline { 2 - 4 } & $\mathrm{N}$ - Hexane & Ethyl Acetate & Water \\
\hline Flavonoid & - & + & + \\
\hline
\end{tabular}

The result of (-) indicates negative flavonoids and $(+)$ indicates positive flavonoids.

While the results of partition extraction from the ethanolic extract obtained n-hexane fraction was $7.61 \mathrm{~g}$ (yield of $2.79 \%$ ), ethyl acetate fraction was $83.77 \mathrm{~g}$ (yield of $30.74 \%$ ) and water fraction was $21.16 \mathrm{~g}$ (yield of $7.76 \%$ ). This indicates a more optimal partition process using ethyl acetate as the solvent. The characterization of the ethanolic extract (Table I).

\section{Flavonoid Screening}

The presence of flavonoids in the n-hexane, ethyl acetate, and water fractions was tested using a color reaction (Shinoda and pew test) and TLC plate. The result of color reaction (Table II).

From the results of the color reaction test showed that the water fraction and ethyl acetate fraction positively contained flavonoids whereas in the $n$-hexane fraction the results were negative, meaning that no flavonoids were found in the nhexane fraction. This is because in general flavonoids are polar, so it would be easy to dissolve in the fraction with a polar solvent or semi-polar solvents such as ethyl acetate and water, so in the non-polar solvent (n-hexane fractions) flavonoids did not extract perfectly.

This is because in general polyphenols and flavonoids are polar, so it would be easy to dissolve in the fraction with a polar solvent or semi-polar so that the fraction of n-hexane non-polar compounds of flavonoids did not extract perfectly.

This is because in general polyphenols and flavonoids are polar, so it would be easy to dissolve in the fraction with a polar solvent or semi-polar so that the fraction of n-hexane non-polar compounds of flavonoids did not extract perfectly.

This is because in general polyphenols and flavonoids are polar, so it would be easy to dissolve in the fraction with a polar solvent or semi-polar so that the fraction of n-hexane non-polar compounds of flavonoids did not extract perfectly.
This is because in general polyphenols and flavonoids are polar, so it would be easy to dissolve in the fraction with a polar solvent or semi-polar so that the fraction of n-hexane non-polar compounds of flavonoids did not extract perfectly.

This is because in general polyphenols and flavonoids are polar, so it would be easy to dissolve in the fraction with a polar solvent or semi-polar so that the fraction of n-hexane nonpolar compounds of flavonoids did not extract perfectly.

To ensure the presence of flavonoids in the water fraction and ethyl acetate fraction, another qualitative test was carried out using Thin Layer Chromatography (TLC). TLC runs using several mobile phases and detected in $254 \mathrm{~nm}$ (Figure 2).

From the results of Figure 2, it was shown that the water fraction and ethyl acetate fraction contained flavonoids. Thus, for certain identification of nicotine, the plate was sprayed with a specific color Dragendorff's reagent. This reagent usually forms an orange-red colored complex in the reaction with alkaloids. Consequently, the characteristic zone of nicotine appears as orange bands on a yellow background of derivatized chromatographic plate (Figure 1). The image of the TLC separation indicates that all analyzed samples contain nicotine. Hus, for certain identification of nicotine, the plate was sprayed with a specific color Dragendorff's reagent. This reagent usually forms an orange-red colored complex in the reaction with alkaloids. Consequently, the characteristic zone of nicotine appears as orange bands on a yellow background of derivatized chromatographic plate (Figure 1). The image of the TLC separation indicates that all analyzed samples contain nicotine.

Thus, for certain identification of flavonoid, the plate was sprayed with a specific color Citroborate's reagent. This reagent usually forms 


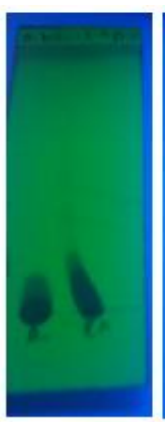

(1)

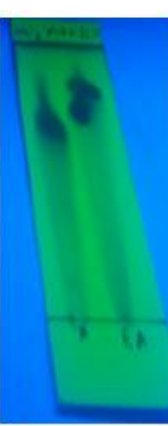

(2)

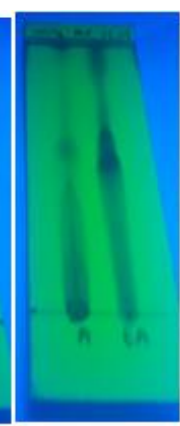

(3)

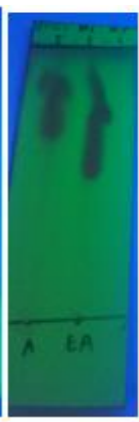

(4)

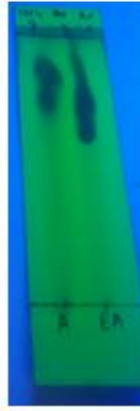

(5)

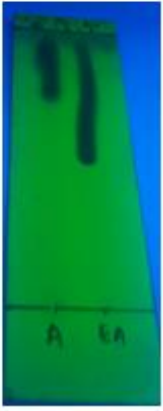

(6)

Figure 2. The TLC separation of flavonoid in UV light detection at $254 \mathrm{~nm}$

A indicate water fraction and B indicate ethyl acetate fraction. The number of 1, 2, 3, 4, 5, 6 indicates several mobile phase. No 1 indicate n-hexane : ethyl acetate (1:1), No. 2 indicate dichloromethane : methanol (2:1), No.3 indicate dichloromethane : methanol (5:1), No. 4 indicate dichloromethane : methanol : water (5:5:1), No. 5 indicate dichloromethane : methanol : water (7:3:1) and No. 6 indicate dichloromethane : methanol : water $(10: 3: 1)$,

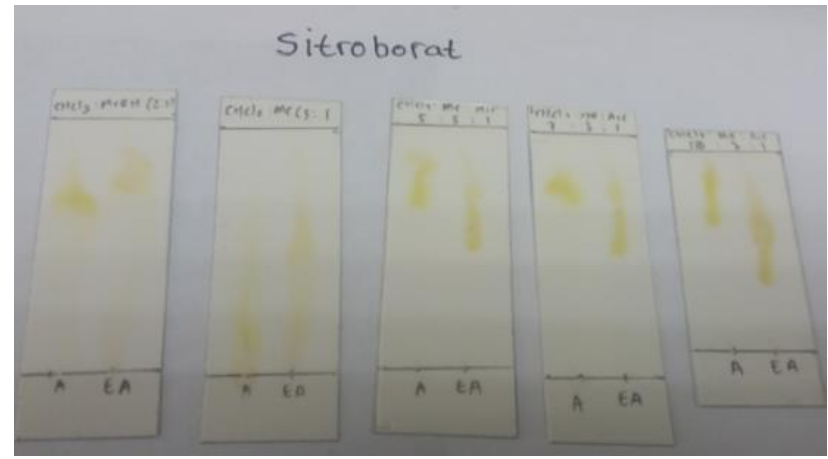

Figure 3. The TLC separation of flavonoids detection in visible light after derivatization with Citroborate's reagent

a yellow colored complex in the reaction with flavonoids and the result of the derivatized chromatographic plate shown that the water and ethyl acetate fraction contained flavonoids (Figure 3).

To determine the total content of flavonoids in the water and ethyl acetate fraction, quantitative testing was carried out using spectrophotometry. Based on quantitative tests of total flavonoids in water and ethyl acetate fraction, it was found that in the water fraction the total flavonoid content was greater than the ethyl acetate fraction, respectively were $0.41 \%$ and $0.25 \%$.

Furthermore, the water and ethyl acetate fraction was selected to hair growth-promoting activity test.

\section{Hair Growth Promoting Activity}

In the hair growth-promoting activity test, the average hair length and weight of rabbit hair were measured. The average hair length is shown in Table III and Figure 4.

From Figure 4, hair growth activity was seen at week 1 . The length of the hair has increased every week in all treatments. The normal controls that do not receive treatment describe normal growth, the hair growth activity is slower than other treatments. The $4 \%$ water fraction at week 4 (day 28) has a significant hair length compared to other treatments.

Hair weight also measured in this study. On week 4, hair shaving was carried out on the test area then the hair was weighed. This hair weight parameter is used to see the effect of each treatment on rabbit hair thickness. The results of hair weight measurements can be seen in Table IV and Figure 5.

The hair weight of each rabbit in each treatment is not significantly different, only in the treatment with a $4 \%$ water fraction between 


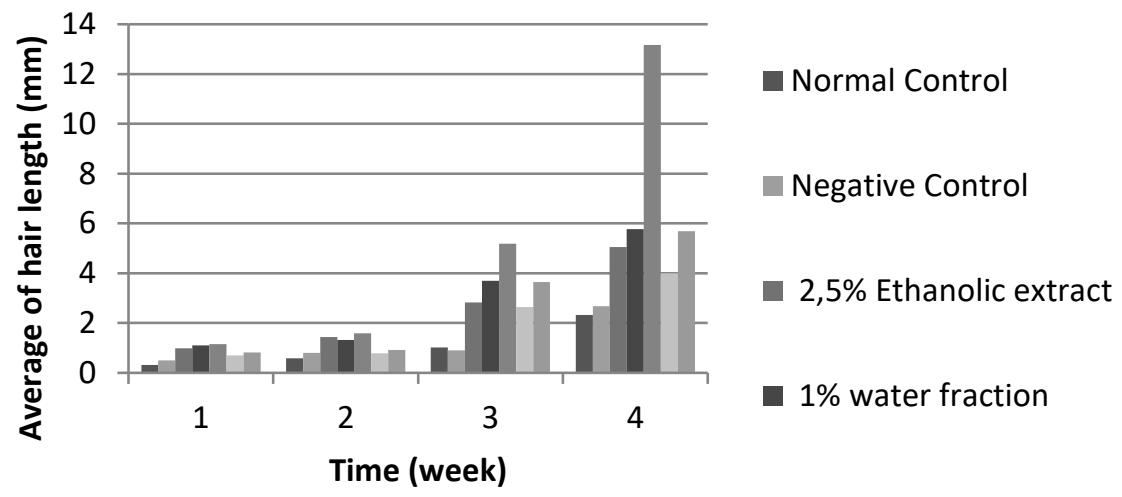

Figure 4. Graph of average of hair length per week

Table III. The average of hair length result

\begin{tabular}{|c|c|c|c|c|}
\hline \multirow{3}{*}{ Treatment } & \multicolumn{4}{|c|}{ The average of hair length (mm) } \\
\hline & \multicolumn{4}{|c|}{ Week } \\
\hline & 1 & 2 & 3 & 4 \\
\hline Normal control & 0.3250 & 0.5820 & 1.0092 & 2.3242 \\
\hline Negative control & 0.4946 & 0.8075 & 1.2538 & 2.6825 \\
\hline $2.5 \%$ ethanolic extract & 0.9929 & 1.4258 & 2.8250 & 5.0667 \\
\hline $1 \%$ water fraction & 1.1004 & 1.3133 & 3.6892 & 5.7763 \\
\hline $4 \%$ water fraction & 1.1617 & 1,5813 & 5.2979 & 10.6233 \\
\hline $1 \%$ ethyl acetate fraction & 0.7075 & 0.7871 & 2.6371 & 3.9938 \\
\hline $4 \%$ ethyl acetate fraction & 0.8225 & 0.9242 & 3.6558 & 5.7217 \\
\hline
\end{tabular}

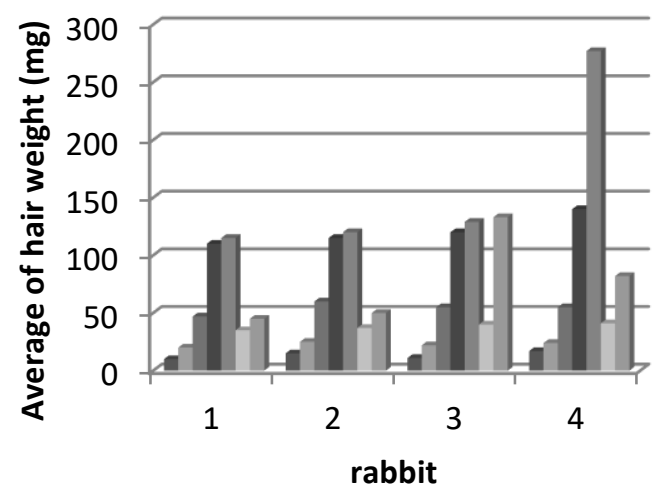

Normal Control

Negative Control

2,5\% Ethanolic extract

$1 \%$ water fraction

Figure 5. Graph of hair weight result

rabbits No. 4 with the other rabbits showed different weight.

The data of hair length and hair weight were analyzed statistically using ANOVA, Mann-Whitney and Kruskal-Wallis test. The ANOVA test has shown that the data of hair length was distributed normally and homogeneous yet the data of hair weight was distributed not normally and not homogenous. Statistical analysis of hair length and hair weight using Mann-Whitney and Kruskal-
Wallis have shown that the increase of hair length and hair weight in treated groups is significantly different when compared to control and negative treated groups $(\mathrm{P}<0.05)$ because in the normal group no treatment was given and in the negative group was only smeared with aquadest. In the group smeared with ethanolic extract showed a significant difference with the group smeared with water and ethyl acetate fraction, because the water and ethyl acetate fraction containing only 
Table IV. Hair weight result

\begin{tabular}{lccccc}
\hline \multirow{2}{*}{ Treatment } & \multicolumn{3}{c}{ Hair weight (mg) in rabbit } & \multirow{2}{*}{ Average (mg) $\mathbf{\pm S D}$} \\
\cline { 2 - 5 } & $\mathbf{R 1}$ & $\mathbf{R 2}$ & $\mathbf{R 3}$ & $\mathbf{R 4}$ & \\
\hline Normal control & 10 & 15 & 11 & 17 & $12.00 \pm 3.30$ \\
Negative control & 20 & 25 & 22 & 24 & $22.33 \pm 2.22$ \\
2.5\% ethanolic extract & 47 & 60 & 55 & 55 & $54.00 \pm 5.38$ \\
1\% water fraction & 110 & 115 & 120 & 140 & $115.00 \pm 13.15$ \\
4\% water fraction & 115 & 120 & 129 & 277 & $121.33 \pm 78.05$ \\
1\% ethyl acetate fraction & 35 & 37 & 40 & 41 & $37.33 \pm 2.75$ \\
4\% ethyl acetate fraction & 45 & 50 & 133 & 82 & $76.00 \pm 40.47$ \\
\hline
\end{tabular}

flavonoids and other compounds according to their polarity while ethanolic extract still contained other compounds which can affect the activity of the ethanolic extract. The group smeared with water fraction showed a significant difference with the group smeared with ethyl acetate fraction because the flavonoid content in the water fraction was more. The $1 \%$ water fraction with a $4 \%$ water fraction also showed a significant difference in significance $(\mathrm{p}<0.05)$, because at greater concentrations, the flavonoid compound content will increase so the hair growth activity will increases.

Based on the results of the statistical study, the $4 \%$ water fraction was given the best hair growth activity compared the other treatment.

\section{CONCLUSION}

Water and ethyl acetate fraction of green tea ethanolic extract contains flavonoids which have hair growth-promoting activities. The $4 \%$ water fraction was given the best hair growth-promoting activity compared to ethyl acetate fraction because the flavonoid content in the water fraction is more than ethyl acetate fraction.

\section{ACKNOWLEDGMENT}

The authors would like to thank the technical staff of the Pharmaceutical Research Laboratory, Faculty of Pharmacy, Pancasila University who have assisted in the implementation of this research.

\section{REFERENCES}

Adhirajan, N., Kumar, D.V. \& Gowri, C., 2008, 'Development and Evaluation of Herbal Formulations for Hair Growth', E-Journal
Chem. 5, 34-38.

Departemen Kesehatan Republik Indonesia, 1995, Farmakope Herbal Indonesia, $1^{\text {st }}$ ed, pp. 6, Direktur Jendral Badan Pengawas Obat dan Makanan, Jakarta.

Departemen Kesehatan Republik Indonesia, 2000, Parameter Standar Umum Ekstrak Tumbuhan Obat, pp. 6-9, Direktorat Pengawasan Tradisional, Direktorat Jenderal Pengawasan Obat dan Makanan, Jakarta

Esfandiari, A. \& Kelly, A.P., 2005, "The effects of tea polyphenolic compounds on hair loss amoung rodents', Journal of the National Medical Association. 97, 1165-1169.

Harborne, J.B., 1987, Metode Fitokimia, $2^{\text {nd }}$ ed, translated by Kosasih Padmawinata \& Iwang Soediro, pp. 147, Penerbit ITB, Bandung.

Harrison, S. \& Bergfeld, W., 2009, 'Diffuse hair loss: its triggers and management', Clev Clin J Med. 76, 361-367.

Lamria, E., 2013, 'Uji Stabilitas Fisik, Aktivitas, Dan Keamanan Dari Sediaan Hair Tonic Yang Mengandung Ekstrak Etanol Teh Hijau (Camellia sinensis L) sebagai Nutrasetika', Skripsi, Fakultas Farmasi Universitas, Jakarta.

Markham, K.R., 1988, Cara Mengidentifikasi Flavonoid, translated by Kosasih Padmawinata \& Sofi Niksolihin, pp. 65-75, Penerbit ITB, Bandung.

Tanaka, S., Saito, M. \& Tabata, M., 1980, 'Bioassay of Crude Drugs for Hair Growth Promoting Activity in Mice by a New Simple Method', Planta Medica Suppl. 1, 84-89.

Thorat, R., 2010, 'Herbal Treatment For Hair Loss', Int J Pharm Technol. 2, 497-503. 